\title{
To Digital or not to Digital: How Mothers are Navigating the Digital World with their Young Children
}

\author{
LAURA TEICHERT \\ University of British Columbia
}

\begin{abstract}
We know many children are using digital tools, such as mobile phones and tablets. Much has been debated about the appropriateness of these tools in the lives of young children (e.g., American Academy of Pediatrics, 2001, 2011; National Association for the Education of Young Children, 2012). Yet, parents are engaged in digital practices. Adults' beliefs about the appropriateness of digital media for children influence the environments they create for young children and potentially influence children's exposure to and interactions with digital tools. This paper describes the digital literacy practices of three families and reports on the tensions mothers felt in whether to allow their children to participate in these practices.
\end{abstract}

Keywords

Young children; parent beliefs; digital media; family literacy; digital literacy

\section{Introduction}

We know many children are using digital tools, such as mobile phones, tablets, electronic toys and/or video games, and are doing so very early in their lives (Common Sense Media, 2013; Marsh, 2004; O’Mara \& Laidlaw, 2011; Steeves, 2014). Although the appropriateness of digital tools in young children's lives has been fervently debated (American Academy of Pediatrics (AAP), 2001, 2011, 2013; Canadian Paediatric Society (CPS), 2015), these debates have often forgotten that parents are engaged in digital practices and will introduce children to digital media, even if only by proxy. Parents/caregivers, whether actively providing children with digital tools or not, enable children's access to technology through their modeling of everyday practices. Children learn to appropriately use tools to solve problems, participate in social activities and engage in "embodied meaning making" (Razfar \& Yang, 2010, p. 114) through their observation of, and association with, more competent members of their communities.

While professional associations and institutions debate the appropriateness of technology for very young children, digital engagement has increasingly been taken up in many western societies. Key stakeholders have raised concerns about screen time, passivity, low activity levels, and about the developmental effects of digital play (e.g., National Association for the Education of Young Children, 2012). These concerns influence educators', parents', and the general public's opinion regarding young children's uses of digital media. Additionally, adults' beliefs about the appropriateness of digital media for children influence the environments they create for young children and 
potentially influence children's exposure to and interactions with digital tools. Some parents limit their children's digital usage while others encourage and value their children's early digital engagement (Davidson, 2009; Marsh, 2004; O'Hara, 2011; Stephen, Stevenson, \& Adey, 2013; Wolfe \& Flewitt, 2010). This paper describes the digital literacy practices of three families and reports on the tensions mothers felt regarding their children's participation in these practices. These practices and tensions are reported for the purpose of illustrating the kinds of decision-making in which parents engage.

\section{Related Research}

Large-scale studies designed to track the digital tools to which the children have access have documented changes in media environments and behaviours. For example, Common Sense Media (2011, 2013) noted a dramatic increase from 2011 to 2013 in young children's access to mobile media devices (e.g., iPads). In 2011, only 8\% of families surveyed accessed an iPad. By 2013, 40\% of families were using tablet technology. Although traditional screen time (e.g., television, DVD) for children between birth and 8years declined, mobile screen time use saw a threefold increase in the two-year period. In Canada, MediaSmarts surveyed 5,436 students between grades 4-11 (all provinces and territories represented) in an attempt to discern how digitally literate Canadian students were and what digital devices were available to them in their classrooms (Steeves, 2014). Of note, $99 \%$ of surveyed students, from around the country, had access to the Internet outside of school.

Researchers have begun observing and documenting young children's and families' digital practices, much like earlier researchers documented the home literacy practices of families (Heath, 1983; Purcell-Gates, 1995; Taylor, 1983). This research has focused on the "techno-literacy practices" (Marsh, 2004, p.52) of families and has described parents' inclusion of children in digital practices (e.g., Marsh, 2004), the explicit instruction parents or older siblings provide young children (e.g., Davidson, 2009; Marsh, 2004; Stephen, Stevenson, \& Adey, 2013), and how children implicitly learn about digital tools (Plowman, McPake, \& Stephens, 2008). Findings from this body of research suggest children are socialized into digital practices through their observation of and interaction with adults and peers who use digital tools (Marsh, 2004; O’Mara \& Laidlaw, 2011) and that children move seamlessly between print-based and digital-based texts in their search for information during learning activities in their homes (Davidson, 2009, 2012; McTavish, 2009).

In addition to documenting what digital tools young children engage with, a team of researchers in Scotland, Plowman, Stevenson, Stephen, and McPake (2012), noted differences between low and high technology homes, the types of digital tools children are using, and how families scaffold children into new electronic toys and video games. Parents believed the "complexity of the interface" (p. 33) could frustrate their children so games or devices requiring plenty of reading were limited to joint play-time (e.g., playing with an older sibling or parent). As well, parents sought to protect their children from becoming "socially isolated" (p. 35) by limiting digital media usage. Parents attempted to strike a balance between "solo and shared, educational and playful, and screen and non-screen activities for their children" (p. 35).

Some parents value new media and children's engagement with digital devices. For example, O'Hara (2011) found that parents believed their children were learning far more than skills such as dexterity or fine motor skills. Parents reported being "proud of the fact 
that their children were developing a technological literacy... necessary to perform simple functions with ICT" (p. 224) such as operating a mouse or logging into a program, at young ages. Schlembach and Johnson (2014) examined parents' views towards screen media and noted parents felt screen media was an important learning tool for children, despite parents not reporting that they actually used this for the purpose of teaching their children. Parents felt it was important to "watch TV, DVD, and video with children and that they 'often or most of the time' intentionally watch programs with their children" (p. 98). Parents acknowledged using a combination of mediation styles, such as allowing children to watch screens independently, so that chores could be more efficiently completed.

Even the AAP (2013) has softened their stance against children's use of technology and media to acknowledge positive and prosocial uses of media and to encourage parentchild co-viewing television and screen-time. In response to the AAP's shift, Connell, Lauricella, and Wartella (2015) examined the factors associated with parent and child couse of media across multiple platforms using survey data from a nationally representative sample of families with children aged eight- years and younger in the United States. These researchers looked at co-viewing habits across six platforms: books, television, video games, computers, tablets, and smartphones and reported five major findings:

1. Parental co-use of most types of media technology is predicted by the amount of time the parent is home with the child.

2. Even controlling for [the amount of time the parent is home] with the child, parent demographics, including gender, age, race, and education, predict media co-use.

3. Child demographics and characteristics also influence parent-child co-use.

4. Parents' own time with media is a strong predictor of parent-child co-use.

5. Demographic variables only explain a marginal amount of the variance of parentchild media co-use and not consistently across all media. (p. 15)

Interestingly, mothers were more likely to co-use books while fathers were more likely to co-use video games with their child. In addition, the researchers found parents were more likely to co-use materials that they use themselves. For example, if they played video games, then they would co-use video games with their child.

However, research also found that parents and caregivers have concerns about the effects of screen time on children's physical and social development and place limitations on children's usage. For example, early childhood educators interviewed by Wolfe and Flewitt (2010) felt technologies could be damaging as "'family-time' and communication can suffer because of children being allowed to absorb themselves within these 'electronic worlds"” (p. 391). Furthermore, the amount of time children access screens has frequently been cited as one of the leading reasons for rising obesity rates among children. For example, in Canada, 26\% of children between 2-17 years of age are overweight or obese (Canadian Obesity Foundation, 2015). Physical activity organizations, such as ParticipACTION, regularly screen television commercials aligning children's decrease in physical activity to their increase in screen-time activity.

In sum, research has highlighted the technology and digital tools to which children have access in their daily lives and has documented how children become socialized into digital literacy practices in their homes and communities. However, little research has focused on how parents make decisions about technology and digital media for their young 
children. This study emphasizes the tension parents experience in deciding whether to expose their children to technology and digital media, and if so, the appropriateness of particular types of technology and digital media they make available and the duration these devices should be used by their children.

\section{The Study}

This study is situated in the sociocultural theory of learning and development (Vygotsky, 1978). Individuals construct new knowledge based on previous experiences and their socially rooted attitudes and values. Sociocultural theories of learning emphasize the social contexts and purposes of meaning making (Hassett, 2006). For this paper I draw data from a set of semi-structured interviews I had with three mothers. The interviews were conducted as part of my larger study and occurred at the study's onset. The larger study examined how children used digital tools and their engagement in digital literacy practices in the context of family life before, and as they transitioned into, kindergarten. The following research questions guided my data collection and analysis:

1. What digital tools are four- and five-year-old children using in their homes?

2. What is the purpose of children's uses of digital tools?

3. How much adult or significant others' mediation or support of digital tool use (if any) is occurring in the homes? What is the nature of this support or mediation (i.e., is digital tool use connected to developing digital literacy in young children)?

The interviews served as an introduction to the digital tools children had access to in their homes and provided information about what digital tools parents used both for themselves and with their children, for example, I asked the mothers:

a. "What devices do you use in your home? How often? For how long? (e.g., how long at a single time? How frequently do you return to the device? What are your purposes for using the device?), and

b. Does your child see you/family members using digital devices? If so, which ones? When? Where? For what purposes?

Interviews were conducted face-to-face, audio-recorded and lasted between 30-40 minutes. In addition to semi-structured interviews, I conducted monthly in-home observations over one calendar year. I recruited my participants by word of mouth. I previously knew two participants before conducting the interview, while a colleague introduced me to one participant. Because of the distance between our homes (Ontario and British Columbia), I interviewed one mother using Skype. In addition to the more structured interview, I engaged in informal interviews (or in the moment conversations) with two parents during participant-observations of their children as a means of clarifying behavior. I transcribed interviews and coded them into broad themes (Leech \& Onwuegbuzie, 2008), using constant comparison analysis. I manually coded interview transcripts using the comment function of Microsoft Word software. This function's design allows writers to manually create notes in the document. I inductively analyzed my data (Lincoln \& Guba, 1985) and based my interpretations of the data on constructs identified in the literature. 


\section{Participants and Settings}

Danielle. ${ }^{1}$ Danielle is a mother of two young boys, aged four and three years, respectively. She, along with her husband and sons, lives in a medium sized city in southwestern Ontario. Danielle and I have known each other for over a decade and were very familiar with each other before conducting the interview. Both Danielle and her husband work; Danielle as a consultant and her husband manages their family business. Danielle completed both a Bachelor and Masters' degree while her husband holds a degree in Engineering. Since they own their own business, her husband is often able to work from home; however, they use her husband's mother for childcare many days a week. In Ontario, kindergarten is a two-year program consisting of junior and senior kindergarten. As such, children enter junior kindergarten the year they turn four years of age. Danielle's eldest son attends kindergarten Monday to Friday at a public elementary school near their home. Danielle owns many digital devices, most of which are in the home. They have a home office with a computer and printer, which they use to run their small business and for Danielle to use to complete her consulting tasks. In addition to the office, the family owns a television (cable and Netflix), three iPads, a video game console, and two laptops. Her sons are allowed access to both the iPad and video game console, however they usually only play video games under their father's supervision.

Lindsay. Lindsay is a single mother raising her daughter in an urban city in the lower mainland of British Columbia. Lindsay was a community acquaintance, as we lived in the same neighbourhood. Lindsay works Monday to Friday in a neighbouring suburb, which involves a daily commute of approximately 30 minutes to work and another 30 minutes home at the end of the day. Her four-year old daughter partakes in this commute, as her daycare centre is located close to Lindsay's work. Lindsay works in the culinary industry, but also has a degree in visual design. During our conversations, Lindsay noted a number of digital tools that both she and her daughter used in the home and/or in the car during their daily commute. Her daughter had access to a variety of digital tools, such as a laptop, Leap Pad, iPad, television (with cable), and audio book. Lindsay used a Blackberry device (which she likes for the keyboard) for personal use and did not make this device available for her daughter's use. Lindsay mentioned that many of the electronic toys in their home were gifts from family and friends, rather than items she had purchased herself.

Sarah. Sarah and I had only spoken once on the telephone before the interview. Sarah is a mother to five- year old twins, a boy and a girl. She lives in a single, detached home with her husband and children in an urban city in the lower mainland of British Columbia. Sarah is a fitness instructor and personal trainer, a job which allows her to work part-time and schedule her own hours. Because of this, Sarah is home with the children and schedules her classes and training sessions around the children's structured activities, such as preschool. Her husband works full-time outside the home as a software developer. Although the children have access to a number of digital tools, such as their father's iPhone, an iPad, and laptop, Sarah and her husband limit the children's time with digital media and typically only allow the children to use these tools with one or both parents. However, sometimes Sarah will stream a video through Netflix for the twins so that she can complete a chore, such as making dinner or doing laundry.

\footnotetext{
${ }^{1}$ All names are pseudonyms
} 


\section{Findings}

In this section, I present the findings from this study as a set of broad themes developed from the research questions. The research questions were:

1. What digital tools are four and five-year-old children using in their homes?

2. What is the purpose of children's uses of digital tools?

3. How much adult or significant others' mediation or support of digital tool use (if any) is occurring in the homes? What is the nature of this support or mediation (i.e., is digital tool use connected to developing digital literacy in young children)?

I directed particular attention to "How much adult mediation or support of digital tool use is occurring in the home?" and "What is the nature of this support or mediation?". The findings from the interviews indicate that, although the three families used digital tools to promote learning and to entertain, the mothers' concerns about their children's lack of physical activity and about their own documenting of their children's lives on social media created tensions that influenced how they structured their children's opportunities to engage with digital technology within the home.

\section{Learning Opportunities}

The notion of learning characterizes the over-arching finding from the interviews: that is, the mothers wanted to provide their children with a variety of experiences from which to learn and engage with the world. The three mothers viewed digital media and technology as one way to teach their children different skills, but not the sole method of engaging children in learning opportunities. All the mothers interviewed shared a strong desire to provide a multitude of experiences and activities for their children to participate in. As well, each described many positive learning opportunities digital tools provided for their children.

Danielle's sons had access to a number of digital tools in their home. They enjoyed playing games on an iPad and playing on their dad's X-Box with him. Danielle described a number of apps she purchased specifically for her sons, including apps that focused on reading, mathematics and shapes. When looking for apps she indicated that she evaluates them for their "educational value", not entertainment. It amazed her how quickly the boys learned how to interact with different technologies. For example, she talked about how she worked from home on a desktop computer, which was password protected and, typically, not used by her sons. Her oldest son was "watching [Danielle] log into the computer and after [watching her] a bit was able to use [her] password", which was a seven-digit code involving numerals and letters.

Sarah also mentioned learning apps she had uploaded to her iPad for her children to use, specifically a drawing app. In our interview she discussed her son's recent "interest in science" and how she then accessed many "science for children" websites that she coviewed with her son. These websites often provided age-appropriate science experiments (e.g., making magic mud) that she or her husband then conducted with the children. Similarly, Lindsay taught her daughter to play the piano and had recently downloaded an app called Garage Band. This app allows users to create their own songs. Users can sing into the app and add beats, musical instruments, increase or decrease the tempo, and so forth to create their own songs. Although Lindsay liked this app, she indicated that she 
wished she "knew how to return to the original track". Lindsay's daughter also owned a Leap Pad device. Lindsay liked that games challenged her daughter and improved her daughter's dexterity. However, not all games are made equally. Lindsay liked the "[Disney Princess] Sophia, the first one. It's good" because "it's a reading one", but felt the My Little Pony game was too easy, in that the game "says 5-8-year-olds but I have a hard time believing it's that, because she's finished it already.".

\section{Entertainment}

In addition to learning, the mothers also expressed a desire to entertain their children. Lindsay mentioned borrowing DVDs from the public library for her daughter to view at home, both individually and with Lindsay. She also downloaded videos onto her iPad for her daughter to watch while Lindsay completed chores around the house. Although Danielle acknowledged her sons were learning skills as they played games on the iPad and $\mathrm{X}$-Box, she also noted that they played these games "for fun". Her sons enjoyed the X-Box not only because the games were fun, but also, because it meant they could spend time with their father.

All three mothers referenced Netflix as a tool for family entertainment. Danielle and her family used Netflix to watch movies and television shows on their large television screen. They also accessed YouTube videos and watched those together on the iPad. Like Danielle, Sarah and her family used Netflix to watch movies. However, Sarah cautioned that "movie night" was a treat, not a daily activity:

I find that if they get into a habit of watching it more regularly, or, now we've started in that last six months having like a movie night on the weekend or something. So that's kind of a treat. But if it's a regular thing...three times a week that is kind of stretching it for me. To the point where they are kind of expecting and asking it, more for it. If it gets to five times a week, that's kind of like, okay, red flags. They now want it every day and they are asking for it a lot and I'm not comfortable with that much time. So I prefer, like one movie night a week, where it is contained and it's like, I don't know, more quality programming too, that we can pick out (Semi-structured interview, March 29, 2015).

The mothers appeared to have concerns regarding their children's engagement with digital tools when used solely for entertainment purposes. When the mothers spoke of their children using digital tools for entertainment they all discussed setting limits for their children's use. Sarah and her husband chose to limit technology for the children to only with a parent. As such, digital tools were used as a family practice, not something the children used and explored on their own. For example, Sarah's husband engaged the children in digital games, such as Angry Birds and The Legend of Sleepy Hollow: Jar of Marbles III, on his iPhone and worked with the children to complete levels. Sarah often told me that "if I didn't limit technology time [her son] would play video games all day". Sarah also shared with me her struggle in how she at times framed access to technology and digital media for her children. She described an incident in which she used the removal of technology from play-time activities as a means of punishment. She explained that over the weekend (prior to my visit) the twins had consciously ruined a piece of furniture in the home and had wasted large amounts of paint. As a result of this behavior, Sarah removed 
digital media from play-time for two weeks. Although firm in her stance, she confided to me that she struggled with this. She did not want technology to be punishment-and-reward, rather, preferring to talk about "bad behavior" with her children. However, these actions were beyond typical actions by the twins and she was "beside herself" with what had occurred.

Danielle was the only mother who reported using extended family in a caregiving role. Between Danielle's consulting job and the small business that she and her husband run, they typically organize a "9-5 work schedule" for themselves. In order for this to work, Danielle used a combination of preschool (for her younger son) and her mother-in-law to care for her sons. As previously mentioned, her eldest son attended full-day kindergarten Monday through Friday. Although Danielle was incredibly thankful that her mother-in-law cared for the boys as frequently as she did, she expressed a dislike with regards to the amount of technology the boys had access to while at their grandma's house. For example, her sons routinely spent the afternoon watching television, both Netflix and children's cable television shows, and ate their lunches while watching videos on the iPad. Danielle said she tried to talk to her mother-in-law about limiting the boys' screen use, but at the time of the interview, little had changed. Because of the increased screen-time at their grandma's house, Danielle tried to limit the boys' screen-time at home, but she acknowledged that, "it becomes a battle".

In sum, the previous sections described the function of digital technology within the home. The mothers discussed the ways their children engaged with digital tools for both learning and entertainment purposes, but also how they tried to limit the children's use of digital tools for entertainment. In the next sections I describe two concerns that led to the mothers' feelings of tension regarding their children's engagement in digital literacy practices.

\section{Physical Activity}

Lindsay tried to promote and encourage physical activity with her daughter. In our interview she spoke of specific measures she took to address what she felt was her daughter's lack of physical activity. For example, she limited her daughter's DVD viewing and engagement with the iPad on the weekends and instead engaged with her in physical, outdoor activities (e.g., playing at the park, swimming), attended educational centres (e.g., museums) during inclement weather, and signed her daughter up for ballet, swimming and gymnastics classes at nearby recreation centres. She expressed her concerns regarding the amount of physical activity her daughter engaged in at daycare and indicated her dislike of the fact that the centre allowed her to nap each afternoon. Although Lindsay tried to limit her daughter's exposure to screens, she mentioned she was concerned her daughter watched "too much TV", but qualified this with "but sometimes, you know, I just need to get things done".

Like Lindsay, Danielle and her husband took steps to ensure their sons engaged in plenty of physical activity, whether it was encouraging them to play in their large backyard, or enrolling their oldest son in organized sports. Unfortunately, their younger son, much to his chagrin, was not yet old enough to participate in organized sports, like Timbit soccer or Timbit hockey. Similarly, Sarah and her husband decided that the twins were "taking a summer break" from video games because they wanted the twins to focus on seasonal activities, such as playing outside in their backyard. Danielle echoed Lindsay's sentiment 
in that she described how she allowed her boys to watch YouTube videos while she prepared dinner. She explained she tries to "listen to what they are watching" but that, she worried, sometimes they were accessing inappropriate material while she was turned around.

\section{Documenting Children's Lives}

Besides the children's active use of technology and digital media, parents routinely display children's images and document children's lives on their own social media networks. Of the mothers I interviewed, Sarah was the only mother to discuss Facebook and her feelings about using the social network to showcase her children. Sarah did not use the site very often as she "just [doesn't] have the time. You get on it and before you know it, it's like 'ohmigod I just spent an hour'. So I nixed that pretty early on." She also discussed her concerns regarding privacy on Facebook and that these concerns kept her from using the social networking site to upload pictures and make comments about her children. She explained her feelings about the site:

Sarah: I'd rather have more privacy. I just found that like, you get friend requests from people that you haven't, that you don't even almost know.

Researcher: You knew 15 years ago in high school, or whatever it was

Sarah: Yeah exactly. That's what I'm thinking of too. So, you know to put your pictures out there for anybody you barely know to see or whatever, I'm just not into it. You know, those are our pictures (Semi-structured interview, March 29, 2015).

However, images of Sarah's children were uploaded to Facebook as her husband occasionally used the site to update far-away friends and family.

In sum, the three mothers interviewed reported using digital tools in their homes with their children to promote learning and to entertain. Children accessed a variety of digital tools, such as televisions, smartphones, tablets and video games. Parents placed restrictions of children's digital use either through time limits or by only allowing children to use particular digital tools with an adult. None of the mothers interviewed reported excluding technology and digital media from their children's lives. However, none were overly positive about the associations of digital media in young children's lives. I will now discuss my findings through the lens of the good mother.

\section{Discussion}

The "good mother" is a compelling construction to which many mothers attempt to model their parenting. Smythe (2006) described the good mother as:

This good mother is found in the powerful cultural image of the smiling, calm, patient, attentive and sympathetic caregiver. She is "involved" (Delhi, 1996), always teaching, guiding, helping out at the school or play group. She is an ideal against which tired and cranky mothers like myself measure ourselves, and forever find ourselves lacking (p. 3).

The standards for the "good mother", although shifting, can powerfully shape mothering experiences "even when women protest and resist these standards" (Smythe, 
2006, p. 5). In the digital age, choices about when to expose children to technology play a role in the idealized good mother. A mother's feelings towards digital media are often woven from contradictions between technology advice from parenting websites and magazines and the reality of the "everyday lives and material conditions that shape mothering" (Smythe, 2006, p. 5).

Of the three mothers interviewed, Sarah spoke most frequently about consciously limiting her children's media intake. Strict limitations were placed on what her children could use, with whom and for how long. As mentioned earlier, Sarah struggled with how to frame technology, not as punishment and reward, but as a treat. She also cautioned that she felt her son would play video games all day if she did not limit his time with digital devices. Danielle also had mixed-feelings about her sons' technology and digital media use. She was fascinated by what they learned on different devices, and how quickly they learned it. But she said, "it's hard". She wants them to continue to learn and feels it is important to use technology, but that she "feels guilty and like it could be bad for them", echoing the sentiments shared by Wolfe and Flewitt's (2010) participants who restricted the amount of time children spent on the computer over concerns about the "effects of screen-based activities on children's overall development" (p. 392). Similarly, Lindsay spoke of wanting to limit technology and digital media for her daughter, but acknowledged that it was omnipresent in that it helped her complete chores more efficiently and made long car rides more palatable for her daughter. All three mothers acknowledged physical activity as a priority for their children and took concrete steps to encourage physical activity, such as limiting digital tool use and enrolling children in organized sports and recreation.

Additionally, the prevalent use of social media may create further concerns for mothers. Kumar (2015) described Facebook as "mothers' third shift", a reference to Hochschild's work on family life "which described the 'second shift' of homemaking work that occurs in addition to paid labor. Kumar argues the 'third shift' encompasses the work parents, often mothers, do in presenting their family life online. However, because of concerns related to the children's privacy, a mother may decide to restrict social media posts regarding their children. Interestingly, a mother's choice to restrict social media postings may not extend to the spouse. For example, in this study, Sarah chose not to post images of her children on Facebook while her husband chose to post images.

And yet, the findings of this study suggest digital tools were not always framed negatively. In many ways digital tools allowed for more "family time" moments. Danielle described the quality time her sons spent playing video-games with their father. As well, she and her boys would watch YouTube videos together, which allowed her to connect with her sons over a shared-viewing experience. Similarly, Sarah commented on the time her twins and their father spent engaged in the Sleepy Hollow iPhone game as "special". Movies were family time treats and something Sarah's entire family shared together. On poor-weather days Lindsay and her daughter enjoyed co-viewing television shows or movies on Netflix. Lindsay would talk to her daughter about the shows they watched in much the same way she did while reading a storybook. Or, when reading a book, Lindsay would supplement her daughter's learning by using the Internet to gain more information on, for example, the origins of a fairy tale. The mothers cherished these digital moments as they did the more "traditional" unplugged moments the families shared together.

Furthermore, researchers have recognized the literacy skills associated with 
children's engagement in digital practices (Dodge, Husain \& Duke, 2011; Larson, 2011; Levy, 2009; Marsh, 2004). Recent research has recognized the potential learning opportunities related to the social practice of watching television as a family. For example, Fisch (2011) advised parents on how they could best co-view television and movies with their children, noting that "something as simple as a line of on-screen text can make a significant difference in parents' (and children's) behavior while watching" (p. 35) and promoted parent prompting during co-viewing moments. Fisch also provided examples parents could employ to maximize interaction during co-viewing moments. This type of co-viewing advice mimics the suggestions parents are often given about how to read to their children and extends the mothering as pedagogy discourse (Smythe \& Isserlis, 2002), whereby the nurturing mother promotes learning opportunities for her child.

When considering Sarah, Lindsay and Danielle in terms of future research, further investigation into adults' digital parenting practices, particularly probing how parents make decisions about digital inclusion and why parents prefer particular digital tools more than non-digital tools, may provide additional insight into the 'digital stress' parents face in parenting their children.

\section{Conclusion}

Digital tools and their use within the home presented unique concerns for the mothers in this study. All expressed concerns that their children engaged in too much screen-time. They worried their children lacked physical activity and were missing out on other experiences while engaged with digital devices. And yet, although the mothers spoke of taking precautions to limit as best they could their children's access to electronic media, they also felt there were positive learning experiences tied to digital tool use. The findings of this study suggest the three families were not absorbed in digital media and technology. Instead, the three mothers described a myriad of experiences, both plugged and unplugged, in which they engaged their children. "Unplugged" experiences, such as going to the library, the swimming pool, museums and other educational centres, and the sharing of storybooks at bedtime, in conjunction with digital activities, formed a multitude of experiences from which the children came to learn about the world around them.

Technology will continue to proliferate in modern society. This study builds on current research in emergent digital literacy by focusing on the digital literacy practices of families in their homes. Along with this proliferation of technology within the home comes advice for parents regarding its use by young children. This study also reports on the tensions three mothers felt regarding their children's engagement in digital literacy practices. Given this study documents three mothers' beliefs about digital media from one interview, broad generalizations cannot be given. Yet, case studies are powerful in that they present participants with space in which to more completely express their thoughts and opinions on the research topic.

\section{References}

American Academy of Pediatrics, Committee on Public Education. (2001). Children, adolescents, and television. Pediatrics, 107(2), 423-426.

American Academy of Pediatrics (2011). Policy statement: Media use by children younger than 2 years. Pediatrics, 128(5), 1-7. Retrieved from: 
http://pediatrics.aappublications.org/content/early/2011/10/12/peds.2011-1753

American Academy of Pediatrics (2013). Policy statement: Children, adolescents, and the media. Pediatrics, 132, 958-961. Doi: 0.1542/peds.2013-2656

Canadian Obesity Foundation (2015). What is childhood obesity?: Statistics. Retrieved from: http://childhoodobesityfoundation.ca/what-is-childhood-obesity/statistics/

Canadian Paediatric Society (2015). Active kids, healthy kids: How much for preschoolers? (1-4 years). Retrieved from: http://www.cps.ca/en/activeactifs/how-much-for-preschoolers.

Common Sense Media, \& Rideout, V. (2011). Zero to eight: Children's media use in America. Common Sense Media. Retrieved from: https://www.commonsensemedia.org/research/zero-to-eight-childrens-media-usein-america

Common Sense Media, Rideout, V. (2013). Zero to eight: Children's media use in America. Retrieved from: http://m.commonsensemedia.org/research/zero-toeight-childrens-media-use-in-america-2013

Connell, S., Lauricella, A., \& Wartella, E. (2015). Parental co-use of media technology with their young children in the USA. Journal of Children and Media, 9(1), 5-21, doi: $10.1080 / 17482798.2015 .997440$

Davidson, C. (2009). Young children's engagement with digital texts and literacies in the home: Pressing matters for the teaching of English in the early years of schooling. English Teaching: Practice and Critique, 8(3), 36-54.

Davidson, C. (2012). Seeking the green basilisk lizard: Acquiring digital literacy practices in the home. Journal of Early Childhood Literacy, 12(1), 24-45.

Dodge, A., Husain, N., \& Duke, N. (2011). Connected kids? K-2 children's use and understanding of the internet. Language Arts, 89(2), 86-98.

Hassett, D. (2006). Signs of the times: The governance of alphabetic print over 'appropriate' and 'natural' reading development. Journal of Early Childhood Literacy, 6(1), 77-103.

Heath, S.B. (1983). Ways with Words: Language, Life, and Work in Communities and Classrooms. New York: Cambridge University Press.

Fisch, S. (2011). Raising the (mommy) bar: Encouraging parent-child interaction during preschool TV. In L.Takeuchi \& R. Steeves (authors), The new coviewing: designing for learning through joint media engagement. New York: The Joan Ganz Cooney Center at Sesame Workshop.

Kumar, P. (March, 2015). Now mothers have a third shift- on Facebook. Retrieved from: http://time.com/3758085/third-shift-social-media/?xid=tcoshare

Larson, L. (2011). Digital readers: The next chapter in e-book reading and response. The Reading Teacher, 64(1), 15-22.

Leech, N., \& Onwuegbuzie, A. (2008). Qualitative data analysis: A compendium if techniques and a framework for selection for school psychology research and beyond. School Psychology Quarterly, 23(4), 587-604.

Levy, R. (2009). 'You have to understand words...but not read them': young children becoming readers in a digital age. Journal of Research in Reading, 32(1), 75-91.

Lincoln, Y., \& Guba, E. (1985). Naturalistic inquiry. Beverly Hills, CA: Sage.

Marsh. J. (2004). The techno-literacy practices of young children. Journal of Early Childhood Research, 2(1), 51-66. 
McTavish, M. (2009). 'I get my facts from the Internet': A case study of the teaching and learning of informational literacy in in-school and out-of-school contexts. Journal of Early Childhood Literacy, 9(1), 3-28.

National Association for the Education of Young Children. (2012). Technology and interactive media as tools in early childhood programs serving children from birth through age 8: A joint position statement of the National Association for the Education of Young Children and the Fred Rogers Center for Early Learning and Children's Media at Saint Vincent College. Washington, DC: NAEYC.

O'Hara, M. (2011). Young children's ICT experiences in the home: Some parental perspectives. Journal of Early Childhood Research, 9(3), 220-231.

O'Mara, J., \& Laidlaw, L. (2011). Living in the iworld: Two literacy researchers reflect on the changing texts and literacy practices of childhood. English Teaching: Practice and Critique, 10 (4), 149-159.

Plowman, L., McPake, J., \& Stephen, C. (2008). Just picking it up? Young children learning with technology at home. Cambridge Journal of Education, 38(3), 303319.

Plowman, L., Stevenson, O., Stephen, C., \& McPake, J. (2012). Preschool children's learning with technology at home. Computers \& Education, 59, 30-37.

Purcell-Gates, V. (1995). Other people's words: The cycle of low literacy. Cambridge: Harvard University Press.

Razfar, A. \& Yang, E. (2010). Digital, hybrid, and multilingual literacies in early childhood. Language Arts, 88(2), 114- 124.

Schlembach, S., \& Johnson, M.L. (2014). Parents' beliefs, attitudes and behaviors concerning their young children's screen media use. Dialog, 17(2), 95-104.

Smythe., S. (2006). The good mother: A critical discourse analysis of literacy advice to mothers in the $20^{\text {th }}$ century (Doctoral dissertation). Retrieved from UBC Retrospective Theses Digitization Project [http://www.library.ubc.ca/archives/retro_theses/].

Smythe, S., \& Isserlis, J. (2002). Regulating women and families: Mothering discourses in family literacy texts. English Quarterly, 34, 30-38.

Stephen, C., Stevenson, O.,\& Adey, C. (2013). Young children engaging with technologies at home: The influence of family context. Journal of Early Childhood Research, 11 (2), 149-164.

Steeves, V. (2014). Young Canadians in a wired world, phase III: Experts or amateurs? Gauging young Canadians' digital literacy skills. Ottawa: MediaSmarts.

Retrieved from: http://mediasmarts.ca/ycww/experts-or-amateurs-gauging-youngcanadians-digital-literacy-skills

Taylor, D. (1983). Family literacy: Young children learning to read and write. New Hampshire: Heinemann Educational Books Inc.

Vygotsky, L. (1978). Mind in Society: The development of higher psychological processes. Cambridge, MA: Harvard University Press.

Wolfe, S., \& Flewitt, R. (2010). New technologies, new multimodal literacy practices and young children's metacognitive development. Cambridge Journal of Education, 40(4), 387-399. 


\section{Author Biography}

Laura Teichert is a PhD candidate in the Department of Language and Literacy

Education at UBC. Before returning to studies, she worked in elementary education and

as an Early Literacy Specialist. Her research interests are in the areas of early literacy and family literacy, particularly young children's digital engagement and families' digital literacy practices in their homes. 